https://www.journal-imab-bg.org

Original article

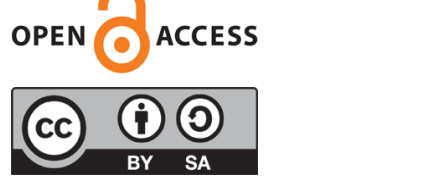

\title{
IMPACT OF MULTIPLE BIRTHS ON THE OUT- COME IN EXTREMELY LOW BIRTH WEIGHT NEWBORNS
}

\author{
Victoria Atanasova ${ }^{1,2}$, Petar Ivanov ${ }^{3,4}$, Elitsa Gyokova ${ }^{2,5}$, Desislava Georgieva ${ }^{6}$, \\ LyubenVeskov ${ }^{1,2}$ \\ 1) Clinic of Neonatology, UMHAT 'Dr. G. Stranski', Pleven, Bulgaria. \\ 2) Department of Obstetrics and Gynecology, Medical University of Pleven, \\ Bulgaria. \\ 3) Clinical Institute for Reproductive Medicine, Pleven, Bulgaria. \\ 4) Department of Biochemistry, Medical University, Pleven, Bulgaria. \\ 5) Clinic of Obstetrics and Gynecology, UMHAT 'Dr. G. Stranski', Pleven, Bul- \\ garia. \\ 6) Home of medical and social care for children, Pleven, Bulgaria.
}

\begin{abstract}
:
Objective: To evaluate the outcome of the extremely low birth weight newborns (ELBWNs) from single and twin pregnancies.

Material and methods: The study lasts from 2005 to 2017 and includes all life born ELBWNs treated in University Hospital, Pleven, Bulgaria. Patients' groups: singletons (1) and twins (2); twins conceived naturally(2.1) and after assisted reproductive technologies - ART(2.2).

Results: One hundred and eighty two (182) ELBWNs are examined, $65(35.7 \%)$ of them are twins. The twins, compared to singletons, are significantly more often conceived by ART (47.7 vs $4.3 \%$, p<0.001) and significantly more rarely infected prenatally (18 vs $41 \%$, p 0.002). The survival rate is $51.3 \%$ for singletons and $56.6 \%$ for twins, NS.

Survived twins (n 37) achieve later their optimal nutritive tolerance $(30 \pm 11$ vs $25 \pm 10$ days, p 0.046), require more blood transfusions $(3.6 \pm 1.9$ vs $2.6 \pm 1.8$ per patient, $p$ $0.009)$ and longer mechanical ventilation $(16 \pm 15$ vs $9 \pm 12$ days, p 0.03) than survival singletons (n 60).

The twins suffer more often from intraventricular haemorrhage (46 vs 18\%, p 0.004), patent ductus arteriosus (35 vs $15 \%$, p 0.02 ) and long-term complications (51 vs $30 \%, \mathrm{p} 0.04$ ) than singletons.

ART-twins (n 31) compared to the subgroup 2.1 (n 34) are more frequently intubated in the delivery room (81 vs. $50 \%, \mathrm{p} 0.01)$ but suffer less frequently from nosocomial infections (53 vs. 85\%, p 0.03).

Conclusions: According to our data, ELBW-twins frequently suffer from respiratory, haemorrhagic, and gastrointestinal problems than ELBW-singletons, resulting in more long-term complications.

Our study proves that ART does not influence the outcome in multiples.
\end{abstract}

Keywords: newborn, twins, extremely low birth weight, assisted reproductive technology, follow-up,

\section{INTRODUCTION:}

Twin pregnancies are an additional risk both for the mother and the fetus/newborn. The increased risk of preeclampsia, hypertension, placental abruption, uterine hyperdistention, and premature birth is presented on the mother side, which results in intrauterine growth restriction (IUGR) and prematurity. The twin-to-twin transfusion syndrome (TTTS) may be an added problem in monochorionic twins. Preterm newborn twins usually suffer more often from respiratory distress syndrome (RDS), intraventricular haemorrhage (IVH), necrotizing enterocolitis (NEC), periventricular leucomalacy (PVL) and long-term neurological complications compared to preterm singletons.

Artificial fertilization / Assisted reproductive technology (ART) is discussed to be an independent risk factor raising not only the rate of multiple pregnancies with all the resulting consequences but also such neonatal complications such as IUGR, birthweight discordance, the higher need for blood transfusions (BT).

With this study, we aim to evaluate the impact of multiple births - from natural and ART-conception, on the morbidity, mortality, and long-term outcome of the extremely low birth weight newborns (ELBWNs).

\section{MATERIALS AND METHODS:}

The study is a retrospective from 2005 to 2015, and after then it is continuing as prospective. It encompasses all ELBWNs born from 2005 to 2017, treated in the Clinic of Neonatology, University Hospital, Pleven, Bulgaria.

Inclusion criteria:

- Life born boys and girls weighed at birth $\leq 1000$ grams;

- Treated in the clinic of neonatology;

- Follow-up to the discharge at home or death.

Exclusion criteria: interruption of follow-up to the discharge at home.

Grouping of the patients: 
- Group 1 - singletons, with Subgroups 1a (survived the discharge at home) and $1 \mathrm{~b}$ (deceased);

- Group 2 - multiples, with Subgroups 2a (survived the discharge at home) and $2 \mathrm{~b}$ (deceased).

The twins are divided additionally according to the conception in subgroups 2.1 (conceived naturally) and 2.2 (from ART). The survivors are divided into subgroups 2.1a and $2.2 \mathrm{a}$, respectively, the deceased - subgroups $2.1 \mathrm{~b}$ and 2.2b.

Followed-up indices: obstetric anamnesis, anthropometric parameters, and gestational age (GA) at birth, morbidity, the outcome at discharge (healthy, with long-term complications, death).

The criteria of viability used are from the International Statistical Classification of Diseases (ICD) 10th Update (birth weight $-\mathrm{BW}, \geq 500$ grams and GA $\geq 22$ gestational weeks - GWs).

GA is assessed by mother's amenorrhea or by New Ballard Score, 1991.

Adequacy of the anthropometric parameters to the GA is measured by Fenton Growth Chart for boys and girls, 2013.

Diagnostic criteria:

- Broncho-pulmonary dysplasia (BPD) - Treatment with oxygen $>21 \%$ for at least 28 days [1]

- Retinopathy of prematurity (RoP) - according to the International Classification of Retinopathy of Prematurity revisited [2]

- NEC - according to the Modified Bell's Staging Criteria for Necrotizing Enterocolitis [3]

- IVH - according to the Modified Papile classification [4]
- Residual cerebral damages - the term include all long-term complications in the brain matter (hydrocephalus, porencephaly, cerebral cysts etc.)

Statistical analysis: The data obtained from infants in both cases and the control group are analyzed using a Student unpaired t-test to find statistical significance. Analysis was performed using STATGRAPHICS plus for Windows 2.1, Microsoft Office Excel 2016, and Windows 10. The p-value $<0.05$ was considered significant.

\section{RESULTS:}

One hundred and eighty-two (182) ELBWNs are examined from the delivery to the discharge. The twins are $35.7 \%$ (n 65) of all ELBWNs. The twins do not significantly differ in BW $(830 \pm 128$ vs $839 \pm 121)$, GA $(26.4 \pm 1.9$ vs $26.8 \pm 2.4)$ and gender (F/M52/48 vs $45 / 55 \%$ ) than singletons. The prenatal steroid prophylaxis is generally low $24 \%$ in Group 1 and $17 \%$ in Group 2, respectively. The twins are significantly more often than singleton conceived by ART (47.7 vs $4.3 \%, \mathrm{p}<0.001)$, delivered via Cesarean section - CS(45 vs 37\%, p 0.048), but more rarely born after premature rupture of membranes - PROM, ( 9 vs $34 \%, \mathrm{p}<0.001)$. Survival rate of both groups is almost identical (51.3\% for Group 1 and 56.6\% for Group 2, NS).

Figure 1 shows the comparative analysis of the morbidity. The twins are significantly less frequently infected prenatally. The incidence of IUGR is high in both groups $-20 \%$ for the twins and $27.4 \%$ for the singletons. Interestingly, it is higher for singletons, although the difference is not significant.

Fig. 1. Morbidity (in \%) of all ELBWNs in both groups

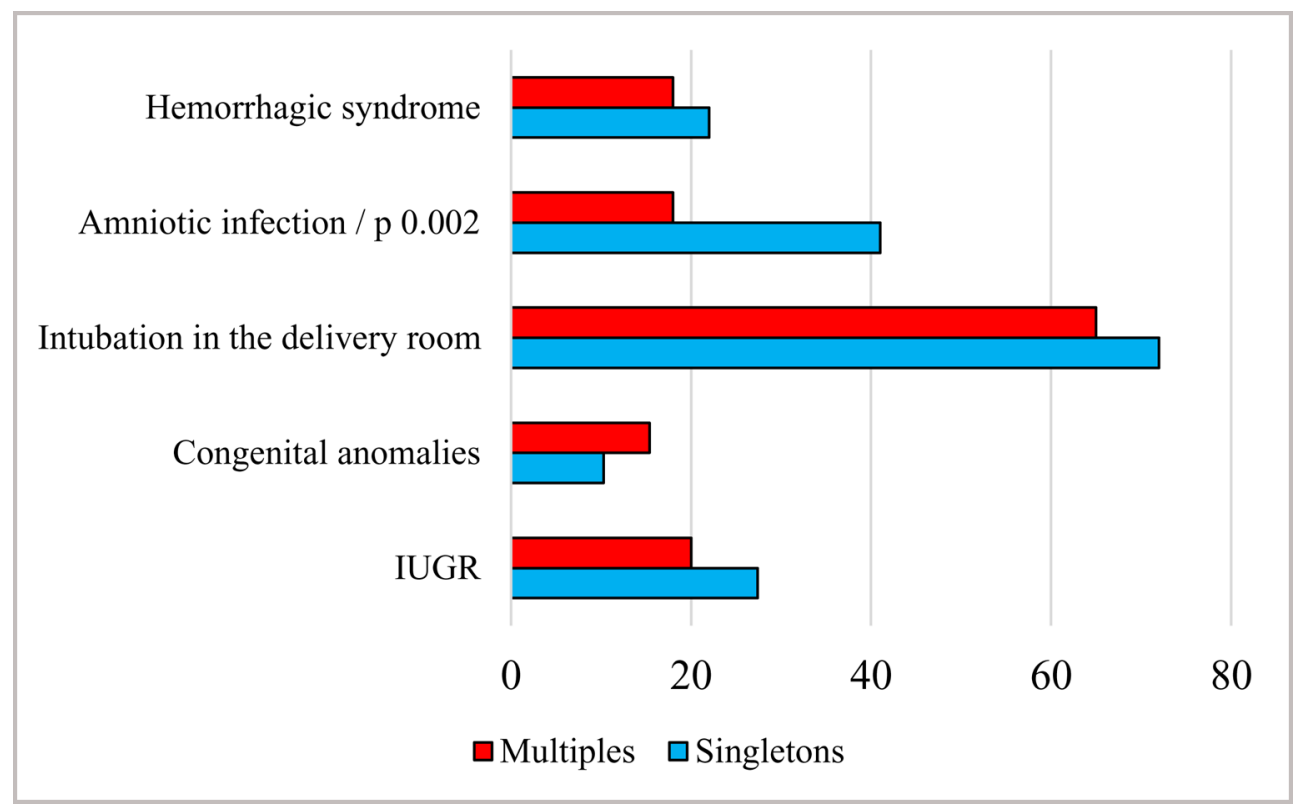

Comparing survivors of both groups, we determine that the survived twins (Subgroup $2 \mathrm{a}-\mathrm{n} 37$ ) achieve later their optimal nutritive tolerance $(30 \pm 11$ vs $25 \pm 10$ days, $p$ $0.046)$, require more blood transfusions $(3.6 \pm 1.9$ vs $2.6 \pm 1.8$ per patient, p 0.009) and longer mechanical ventilation ( $16 \pm 15$ vs $9 \pm 12$ days, $p$ 0.03) than survival singletons (Subgroup $1 \mathrm{a}-\mathrm{n} 60$ ).

Figure 2 shows the mortality of survived ELBWNs 
- twins and singletons. The twins often suffer from IVH, patent ductus arteriosus (PDA) and residual cerebral damages.

Fig. 2. Morbidity of survivors - singletons (1a) and multiples (2a), in \%

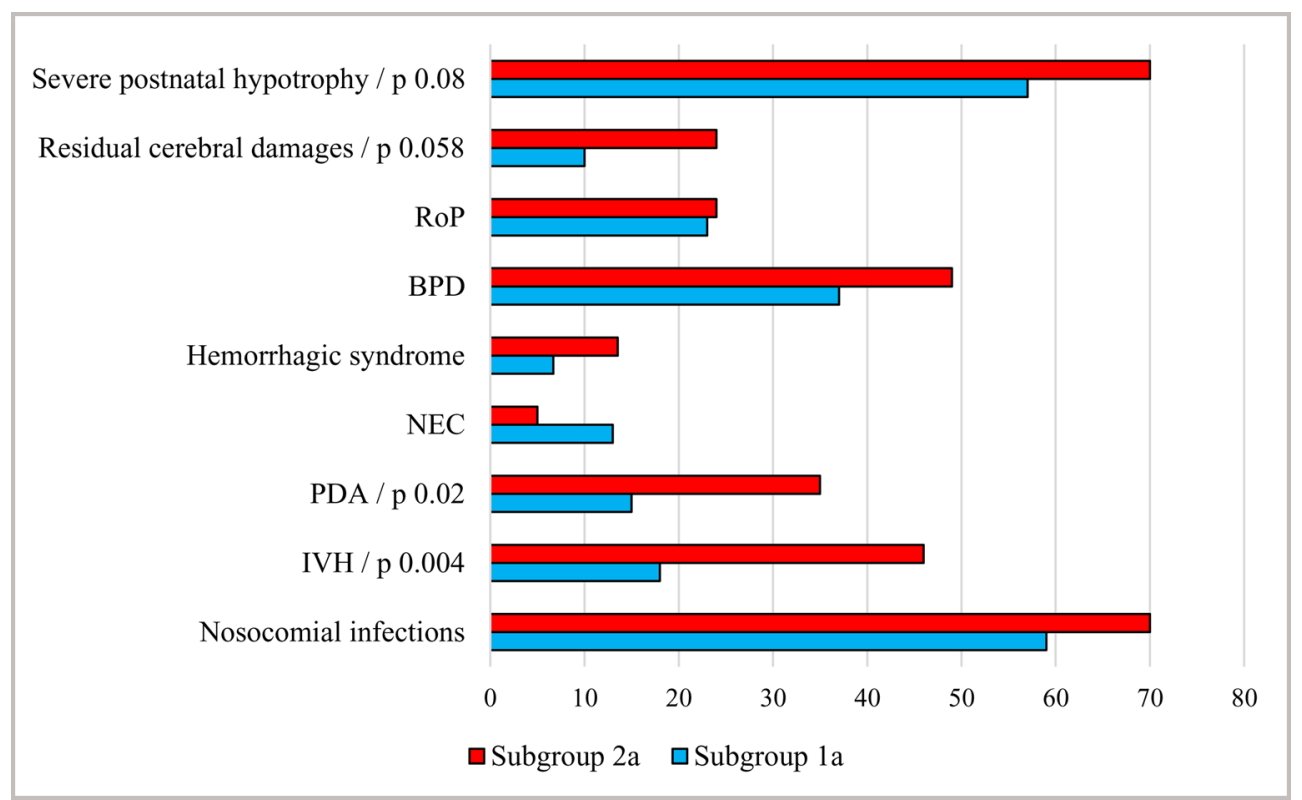

The higher morbidity of twins results in longer hospital stay $(119 \pm 55$ vs $95 \pm 25$ days, p 0.004$)$ and a higher rate of discharged at home with residual problems (51 vs $30 \%, \mathrm{p} 0.04)$ than singletons.

Comparing the deceased singletons (Subgroup 1b n 57) and twins (Subgroup 2b - n 28), we do not establish a significant difference between groups according to the BW(786 \pm 118 vs $782 \pm 130)$, GA $(26.2 \pm 2.4$ vs $26.1 \pm 2.0)$ and gender (60 vs $54 \% \mathrm{M}$ ). The steroid prophylaxis is exceptionally low again $-21 \%$ for singletons and $14 \%$ for twins. The deceased twins are characterized by a significantly lower rate of PROM (11 vs 33\%, p 0.003), a higher rate of ART pregnancies (50 vs $7 \%, \mathrm{p}<0.001)$, more often are delivered in pathologic position ( 28 vs $12 \%$ ) and rarely - via normal delivery (36 vs $53 \%$ ).

Figure 3 shows the morbidity of deceased ELBWNs. The only difference between them is the less need for intubation in the delivery room of the deceased twins, despite the fact that the Apgar score on the first minute is low both for the singletons and the twins $(2.8 \pm 1.7$ vs $3.3 \pm 1.9$, respectively, NS). These values indicate severe depressive condition at birth according to ICD 10th.

Fig. 3. Morbidity of deceased - singleton (1b) and multiples (2b), in \%

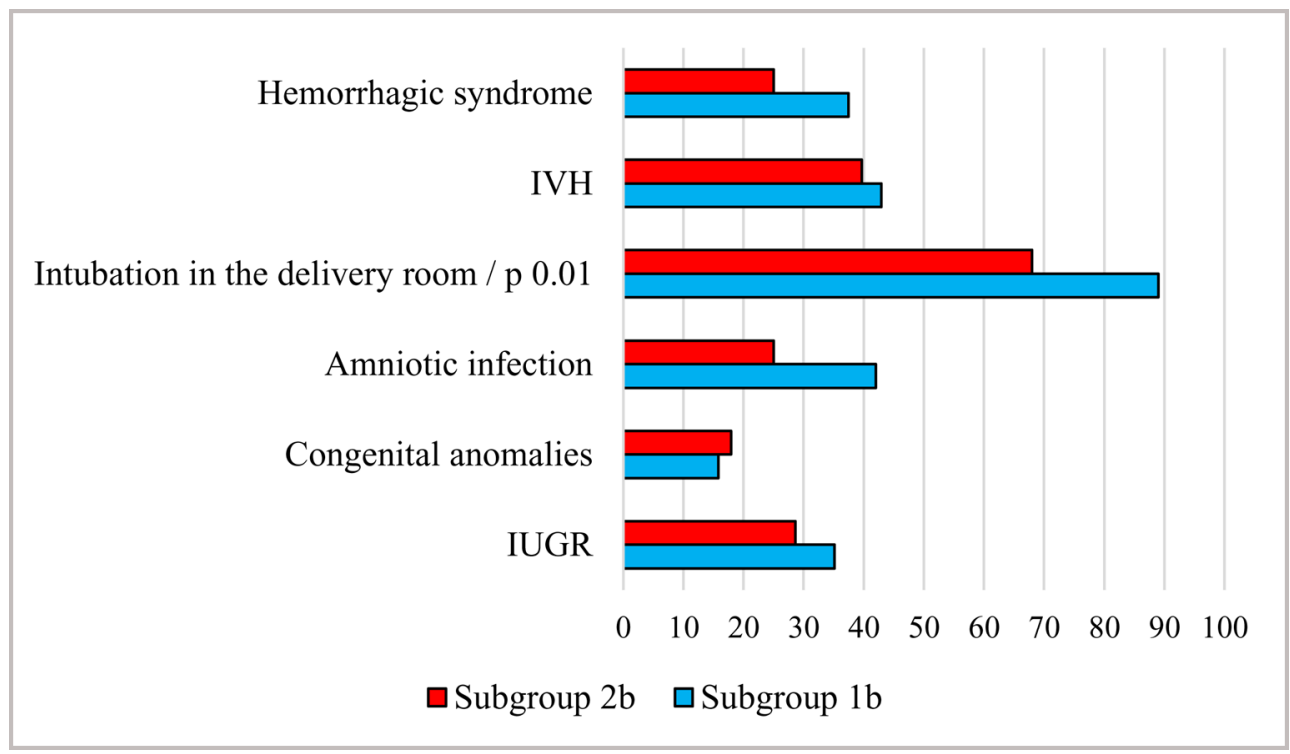


The twins are examined additionally according to their conception. ART-twins (n 31), compared to the twins from natural conception ( $\mathrm{n} 34$ ), do not differ in BW $(834 \pm 122$ vs $826 \pm 135)$, GA $(26.2 \pm 1.7$ vs $26.6 \pm 2.0)$ and gender (45 vs $50 \% \mathrm{M})$, are delivered more often via CS (65 vs $27 \%, \mathrm{p} 0.009$ ). Prenatal steroids (13 vs $21 \%$, NS) and PROM
(6 vs $12 \%$, NS) are equally low in both groups, the survival rate is comparable (55 and 59\%, NS).

Figures 4 and 5 show the morbidity analyzes of the twins. The ART-twins are more often intubated in the delivery room, but they suffer less often from nosocomial infections.

Fig. 4. Morbidity of multiples conceived naturally (2.1) and after ART (2.2) in \%

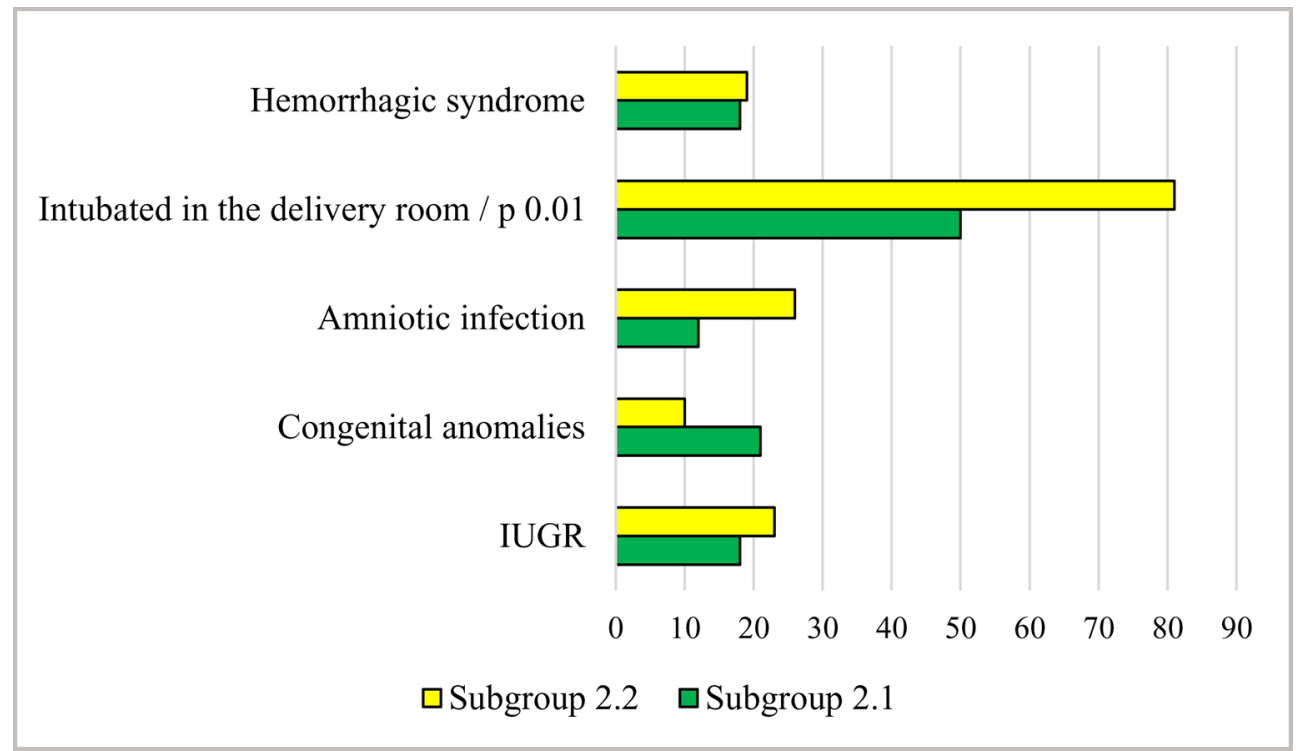

Fig. 5. Morbidity of survived multiples conceived naturally (2.1a) and after ART (2.2a) in \%

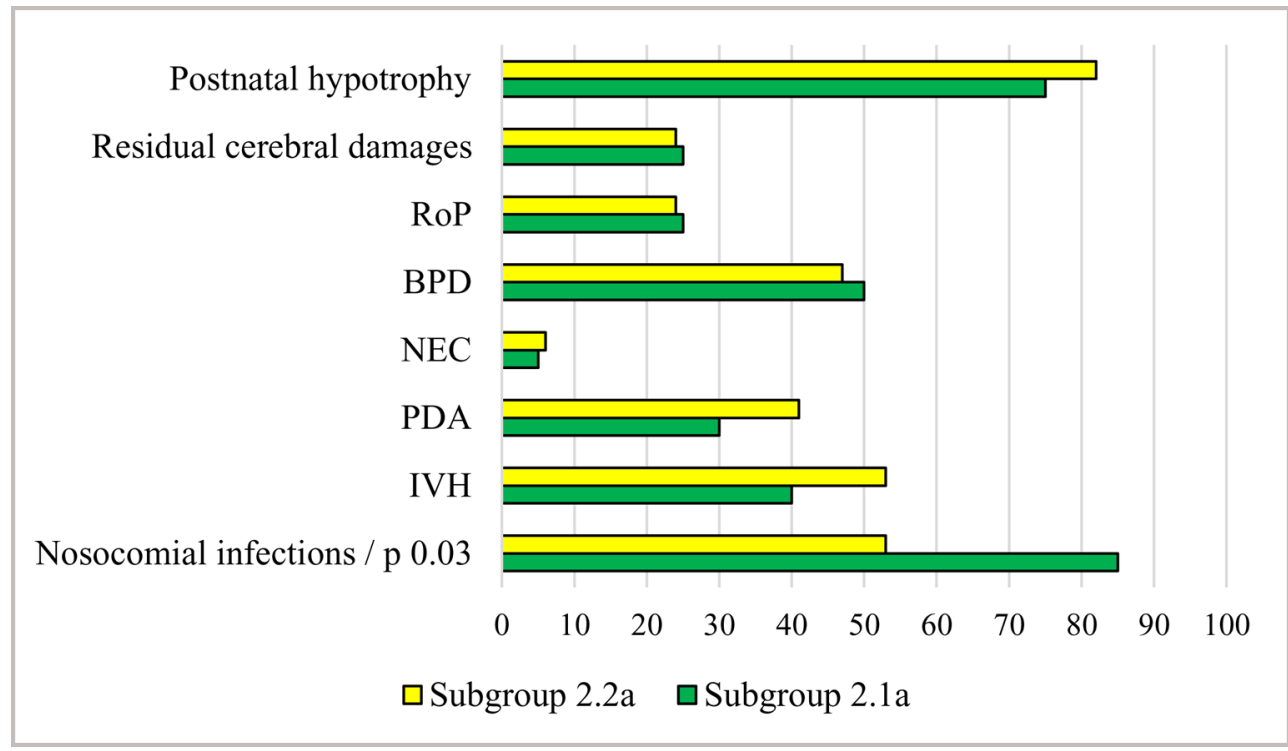

\section{DISCUSSION:}

Multiple pregnancies account for a small percentage of overall live births, but their rate has increased by $76 \%$ in the past three decades in industrialized nations because of increased utilization of ART and an increased risk of spontaneous twinning in women delaying childbearing. [5] Multiple pregnancies compared to singleton pregnancies are at higher risk of preeclampsia and other hypertensive disorders, placental abruption, postpartum hemorrhage, venous thromboembolism, and hypertensive disorders, which increase significantly maternal morbid- ity and mortality. The multiple pregnancies in a large percentage of cases end with premature birth. It is estimated that 1 in 10 twins are born before 32 weeks compared with 1 in 100 singleton births. This is due to uterine over distension and the shortening of the cervix. [6]

Both zygosity and chorionicity affect the outcomes of multiple gestations. The incidence of monozygotic twins is constant worldwide, approximately four per 1000 births. However, the incidence of monozygotic and multi zygotic pregnancies varies in relation to maternal age, the use of ART, and ethnicity. Monozygosity has been related 
to higher rates of congenital anomalies, and chorionicity is known to affect the risk of growth discordance and IUGR. The important risk factor in pregnancy outcome is placental architecture and physiology. Monochorionic twins are at greater risk of morbidity and mortality than dichorionic. Complications like stillbirth, neonatal mortality, congenital malformations, and cerebral palsy are thought to be related to placental sharing and the vascular anastomoses that may cause unequal distribution of placental blood flow, causing TTTS. TTTS is usually presented in the second trimester with oligohydramnios of the donor twin and polyhydramnios of the recipient twin. Monochorionic monoamniotic (MCMA) twins are at greater risk for these complications than monochorionic diamniotic multiples, but MCMA multiples also frequently face growth discordance IUGR and cord entanglement. $[5,7,8]$

Prematurity is the main reason for higher morbidity and mortality of the twins compared to the singletons - a fivefold increased risk of stillbirth and a sevenfold increased risk of neonatal death. [9] According to our data, the insufficient prenatal steroid prophylaxis, higher rate of intrauterine hypotrophy and severe intrapartum asphyxia aggravate the morbidity of these patients. Residual problems are presented mainly by broncho-pulmonary dysplasia and consequences of intraventricular hemorrhage. [10]

The newborn twins are at a higher risk of RDS[11], IVH, PVL, sepsis, NEC. Surviving multiples have higher rates of cerebral palsy and developmental handicap. Some authors affirm that such major morbidities as IVH, PVL, RoP, NEC, PDA, and nosocomial infections, as well as the length of hospital stay, demonstrate no statistical difference between singleton and multiples premature babies. [12]

According to our study, both the longer mechanical ventilation and higher rate of PDA prove more severe respiratory problems in twins in our unit compared to the singletons. Difficulties of achieving the optimal nutritive tolerance and a higher rate of severe postnatal hypotrophy are evidence of gastrointestinal problems in our multiples.

The Higher fetal number correlates with increased risk of IUGR, earlier delivery, prolonged hospital stay, major handicap and cerebral palsy, and death in the first postnatal year. [5] Divergence from singleton growth curves occurs at approximately 32-33 weeks in twin gestations, at 29-30 weeks in triplet gestations, and at 2728 weeks in quadruplet gestations. Blickstein et al. have evaluated the neonatal mortality rate among discordant twins classified according to the birth weight of the smaller twin. The authors showed significantly higher neonatal mortality among twin pairs in whom the smaller twin was small for gestational age. [13] The risk of cerebral palsy in multiple-fetus pregnancies parallels decreasing gestational age. A second association during the late preterm period (34-37 weeks' gestation) may correlate with the increasing maternal morbidities of multiple- fetus pregnancies during this time frame (i.e., fetal growth restriction, hypertensive disorders, placental insufficiency). [14] In a prospective cohort study of monochorionic twins followed from the first trimester to a mean age of 24 months, Ortibus et al. found that TTTS and ART conception increased the risk of both death and neurodevelopmental impairment, whereas early onset discordant growth increased only the risk of death. [15]

According to our data, a higher incidence of the haemorrhagic syndrome and IVH as well and higher need for blood transfusions indicate both hemostatic and hematopoietic disturbances in the twin group. Higher incidence of IUGR and congenital anomalies as well and insufficient corticosteroid prophylaxis in our ELBWNspopulation are aggravating factors for both groups. All these problems in our twin group result in longer hospital stay and a higher rate of residual cerebral damages.

It is proven that ART is an independent risk factor in singleton pregnancies for Cesarean delivery, preterm birth, IUGR, blood transfusions, prolonged hospital stay and mortality. ART multiples suffer additionally from birthweight discordance. [5] ART has been reported to affect mortality and perinatal outcomes in extremely low gestational age infants. [16, 17] Twins born as a result of ART have been reported to have a lower risk of perinatal death compared with naturally conceived twins. The number of embryos transferred may also influence perinatal outcomes. [18] No significant differences were identified in mortality or major neonatal morbidities between triplets who were very low birth weight or very preterm and matched singletons. [19]

According to our data, a lower incidence of amniotic infections and PROM leads to the conclusion that ART is a factor for better clinical control of the pregnancy. ART pregnancies are delivered more often by CS as a striving for protection.

Although ELBWNs of multiple gestation births are at increased risk of mortality compared with singletons, there is an indication that this difference may be diminishing. [20]

\section{Limitations of our study}

It is a retrospective study until 2015 and unpreventable impacts of social, economic, personal, and ethnic factors on our results. The effect of zygosity and chorionicity was not examined because of the lack of data in this regard. Furthermore, this data reflects the experience of a single institution.

Throughout the study period, the borders between abortion and birth in Bulgaria have changed several times. This may have affected the registration of the pregnancy outcome as abortion or birth. This means that it is possible to not include fetuses with signs of life according to the criteria of viability limits of ICN 10th because of the lack of their NICU admission and their registration as abortion.

Therefore, extrapolations and interpretations of our results must be made with caution.

Our study continues, and summarizing the latest re- 
sults is forthcoming to date. We have proposed to other Bulgarian neonatal wards to join us and create a database of ELBWNs for Bulgaria and to publish the results of the study of this specific contingent of patients at the national level.

\section{CONCLUSIONS:}

We prove a higher incidence of respiratory, haemorrhagic and gastrointestinal problems in our twins d"1000 grams BW. They have a greater need for blood transfusions than ELBW-singleton. Consequently, they are hospitalized longer and are discharged with more longterm complications than a singleton.

According to our data, ART does not influence the outcome in multiples according to those conceived naturally.

There is clear evidence that our obstetric care is insufficient but preventable if the reasons of IUGRare resolved timely, the congenital anomalies and amniotic infections are diagnosed prenatally, and the best mode of delivery is chosen opportunely.

In summary, we suggest that early recognition of risk factors and increased awareness of risks associated with preterm birth in twin pregnancies is important. A close collaboration between obstetricians and neonatologists is advised.
Abbreviations:
ELBWNs - Extremely low birth weight newborns
ART - Assisted reproductive technologies
IUGR - Intrauterine growth restriction
TTTS - Twin-to-twin transfusion syndrome
RDS - Respiratory distress syndrome
IVH - Intraventricular haemorrhage
NEC - Necrotizing enterocolitis
PVL - Periventricular leucomalacy
BT - Blood transfusions
GA - Gestational age
ICD - International Statistical Classification of Dis- eases
BW - Birth weight
GWs - Gestational weeks
BPD - Broncho-pulmonary dysplasia
RoP - Retinopathy of prematurity
CS - Cesarean section
PROM - Premature rupture of membranes
PDA - Patent ductus arteriosus
MCMA - Monochorionic monoamniotic

\section{REFERENCES:}

1. Jobe AH, Bancalari E. Bronchopulmonary Dysplasia. Am J Respir Crit Care Med. 2001 Jun;163(7): 1723-9. [PubMed]

2. International Committee for the Classification of Retinopathy of Prematurity. The International Classification of Retinopathy of Prematurity revisited. Arch Ophthalmol. 2005 Jul;123(7):991-9. [PubMed]

3. Caplan MS, Jilling T. New concepts in necrotizing enterocolitis. Curr Opin Pediatr. 2001 Apr;13(2): 111-5. [PubMed]

4. Inder TE, Perlman JM, Volpe JJ. Chapter 24 - Preterm IVH/ Posthemorrhagic Hydrocephalus. In: Volpe's Neurology of the Newborn. 6th Edition. Elsevier. 2018. Pages 637-698.e21. [다ossref]

5. Broughton DE, Jungheim ES. 7 - Multiple Gestations and Assisted Reproductive Technology. In: Avery's Diseases of the Newborn. Tenth Edition. Editors Gleason CA, Juul SE. Elsevier. 2018. Part II. Chapter 7, pp.70-77.e4. [Crossref]

6. Franca MS, Hamamoto TENK, Moron AF. Preterm Birth in Twins. In: Multiple Pregnancy - New Challenges. Edited by Elito J. Jr.
IntechOpen. December 14th 2018. Chapter 9, p.684. [Crossref]

7. Hack KE, Derks JB, Elias SG, Franx A, RoosEJ, Voerman SK, et al. Increased perinatal mortality and morbidity in monochorionic versus dichorionic twin pregnancies: clinical implications of a large Dutch cohort study. BJOG. 2008 Jan;115(1): 58-67. [PubMed]

8. ACOG Practice Bulletin No. 144: Multifetal gestations: twin, triplet, and higher-order multifetal pregnancies. Obstet Gynecol. 2014 May; 123(5):1118-32. [PubMed]

9. Shinwell ES. Neonatal morbidity of very low birth weight infants from multiple pregnancies. Obstet Gynecol Clin North Am. 2005 Mar; 32(1):29-38, viii. [PubMed]

10. Atanasova V. Follow up of physical and neuropsychological development of children born before 33rd GW [in Bulgarian] MedInfo. 2017; 01:64-67.

11. Qiu X, Lee SK, Tan K, Piedboeuf B, Canning R; Canadian Neonatal Network. Comparison of singleton and multiple-birth outcomes of infants born at or before 32 weeks of gestation. Obstet Gynecol. 2008
Feb;111(2 Pt 1):365-71. [PubMed]

12. Garite TJ, Clark RH, Elliott JP, Thorp JA. Twins and triplets: the effect of plurality and growth on neonatal outcome compared with singleton infants. Am J Obstet Gynecol. 2004 Sep;191(3):700-7. [PubMed]

13. Blickstein I, Goldman RD, Mazkereth R. Risk for one or two very low birth weight twins: a population study. Obstet Gynecol. 2000 Sep;96(3):400-2. [PubMed]

14. Wright VC, Chang J, Jeng G, Macaluso M; Centers for Disease Control and Prevention (CDC). Assisted reproductive technology surveillance-United States, 2005. MMWR Surveill Summ. 2008 Jun 20;57(5):1-23. [PubMed]

15. Ortibus E, Lopriore E, Deprest J, Vandenbussche FP, Walther FJ, Diemert A, et al. The pregnancy and long-term neurodevelopmental outcome of monochorionic diamniotic twin gestations: a multicenter prospective cohort study from the first trimester onward. Am J Obstet Gynecol. 2009 May;200(5):494.e1-8. [PubMed]

16. Garg P, Abdel-Latif ME, Bolisetty S, Bajuk B, Vincent T, Lui 
K. Perinatal characteristics and outcome of preterm singleton, twin and triplet infants in New South Wales and the ACT, Australia (1994-2005). Arch Dis Child Fetal Neonatal Ed. 2010 Jan;95(1):F20-4. [PubMed]

17. Helmerhorst FM, Perquin DA, Donker D, Keirse MJ. Perinatal outcome of singletons and twins after assisted conception: a systematic re- view of controlled studies. BMJ. 2004

Jan 31;328(7434):261. [PubMed]

18. Sullivan EA, Wang YA, Hayward

I, Chambers GM, Illingworth P, McBain

J, et al. Single embryo transfer reduces the risk of perinatal mortality, a population study. Hum Reprod. 2012 Dec;27(12):3609-15. [PubMed]

19. Shah PS, Kusuda S, Hakansson

S, Reichman B, Lui K, Lehtonen L, et al. Neonatal outcomes of very preterm and very low birth weight triplets. Pediatrics. 2018 Dec;142(6): e20181938. [PubMed]

20. Yeo KT, Lee QY, Quek WS, Wang YA, Bolisetty S, Lui K, et al. Trends in Morbidity and Mortality of Extremely Preterm Multiple Gestation Newborns. Pediatrics. 2015 Aug;136(2):263-71. [PubMed]

Please cite this article as: Atanasova V, Ivanov P, Gyokova E, Georgieva D, Veskov L. Impact of multiple births on the outcome in extremely low birth weight newborns. J of IMAB. 2021 Jul-Sep;27(3):3985-3991.

DOI: https://doi.org/10.5272/jimab.2021273.3985

Received: 11/02/2021; Published online: 29/09/2021

\section{Address for correspondence:}

Victoria Atanasova

Clinic of Neonatology, UMHAT 'Dr. G. Stranski', Pleven; Department of Obstetrics and Gynecology, Medical University of Pleven,

91, Gen. Vladimir Vazoff Str., Second Clinical Base Pleven, Bulgaria

E-mail: victoria_atanasova@yahoo.co.uk 